\title{
Re-authoring life narratives of trauma survivors: Spiritual perspective
}

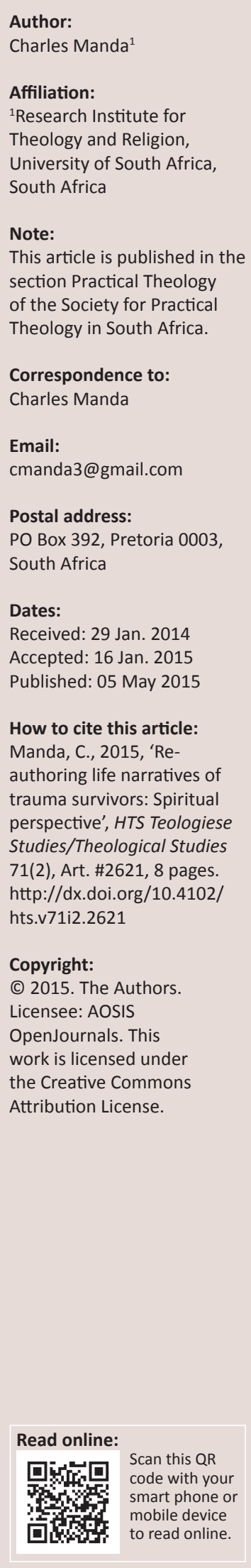

Traditionally, the exploration of the impact of trauma on trauma survivors in South Africa has been focused mainly on the bio-psychosocial aspects. The bio-psychosocial approach recognises that trauma affects people biologically, socially and psychologically. In this article, the author explores a holistic understanding of the effects of trauma on people from communities historically affected by political violence in KwaZulu-Natal, South Africa. Using a participatory action research design (PAR) as a way of working through trauma, a longitudinal study was conducted in Pietermaritzburg from 2009-2013. At the end of the study, life narratives were documented and published. The textual analysis of these life narratives reveals that, besides the bio-psychosocial effects that research participants experienced during and after the trauma, they also sustained moral and spiritual injuries. Trauma took its toll in their lives emotionally, psychologically, spiritually, morally and in their relationships with themselves, others and God. From these findings, the author argues that the bio-psychosocial approach is incomplete for understanding the holistic effects of trauma on the whole person. Therefore, he recommends the integration of the moral and spiritual aspects of trauma to come up with a holistic model of understanding the effects of trauma on traumatised individuals. The holistic model will enhance the treatment, healing and recovery of trauma survivors. This, in turn, will alleviate the severe disruption of many aspects of psychological functioning and well-being of trauma survivors caused by the effects of trauma.

\section{Introduction: The context and purpose of the study}

This study is located in Pietermaritzburg and its surrounding areas such as the Greater Edendale Valley, Mpophomeni and Howick in the KwaZulu-Natal Province. These areas were greatly affected by political violence in the late 1980s and early 1990s, culminating in the Seven Days War which was fought in 1990 between the African National Congress (ANC) and the Inkatha Freedom Party (IFP). Despite the change from Apartheid to a democratic government, South Africa continues to experience multiple-woundedness through trauma and the burden of disease. The effects of this 'multiple-woundedness can be seen everywhere in South Africa, and it is hampering the true political and economic development as so many people have to live with pain. This pain prevents them from making a significant contribution to their communities (Denis, Houser \& Ntsimane 2011:2). Buckenham (1999:7-8) is correct when stating the following, 'South African society is a deeply traumatised community of women, men and children. Each person has a story to tell about themselves, their friends, their family.' Buckenham (1999:7-8) adds: 'In the struggle for survival and liberation, there was (and, for many, is) little energy, space or time to pay attention to these wounds.' She argues that daily survival in an increasingly difficult economic environment is frequently added to existing emotional and psychological trauma and rage.

To facilitate the process of healing from trauma, the researcher set up a Trauma Healing Project at the Pietermaritzburg Agency for Christian Social Awareness (PACSA) in 2009. Using participatory action research (PAR), he joined with trauma survivors to explore the individual and community narratives that the trauma survivors had about their lives and relationships, the effects and meanings of the trauma and the context in which they had been formed and authored (Morgan 2000:10). Thus, the researcher did a longitudinal study spanning five years (2009-2013). During this time, life narratives of trauma survivors were listened to, documented and published in a book. This article is a reflection on both the process and the textual analysis of the life narratives of trauma survivors. It is also a critique of the bio-psychosocial approach which argues that trauma affects people biologically, socially and psychologically. This article argues that the bio-psychosocial approach is incomplete for a holistic understanding and treatment of trauma survivors. Therefore, it calls for the consideration of moral and spiritual aspects as well. The evidence will show that some trauma survivors sustain moral and spiritual injuries during and in the aftermath of a traumatic event. 


\section{Conceptual framework} What is trauma?

The word 'trauma' originates from a Greek word meaning 'to tear' or 'to rupture'. In the case of psychological trauma, this understanding is reflected in the notion of psychological wounding and the penetration of unwanted thoughts, emotions and experiences into the psyche or being of the person (Kaminer \& Eagle 2010:2). Van der Merwe and Gobodo-Madikizela (2008:158-182) see trauma as a special form of memory, and the traumatic experience has affect only, not meaning. It produces emotions such as terror, fear, shock and, above all, a disruption of the normal feeling of comfort. The sensation-factor sector of the brain is active during trauma, but the meaning-making faculty, the rational thought and cognitive processing, namely the cerebral cortex, remains shut down because the affect is too much to be registered cognitively in the brain. Since experience has not been given meaning, the person who experienced the trauma is continually haunted by it in dreams, flashbacks and hallucinations. When the traumatic memory is not processed, it becomes a debilitating memory, and it places excessive demands on people's existing coping strategies. Furthermore, it creates severe disruption in many aspects of the psychological functioning and well-being of a survivor (Kaplan \& Wang 2004:5). Landau, Mittal and Wieling (2008:194) argue that the scope of damage that mass trauma causes in a family is often underestimated. They observe that we tally the number of people killed or injured, the number of homes lost and the dollars spent on emergency aid, but we seldom measure the more subtle costs such as the increase in depression and anxiety, substance abuse and addiction, risky sexual behaviour, child abuse and couple violence. They also argue that we rarely mention the impact of these factors across extended families as their neighbourhoods and urban settings suffer an increase in poverty, street and orphaned children and crimes such as bank robberies, rapes, armed assaults and car robberies.

The effects mentioned above are rife in South Africa. This demands attention and intervention. For healing to occur, space needs to be created for trauma survivors to work through trauma. Van der Merwe and Gobodo-Madikizela (2008:viii-ix) contend that the healing of trauma survivors does not imply an end to all pain and suffering but rather facing and working through trauma so that the tragic loss caused by trauma is balanced by a gain in meaning.

\section{Research process}

This participatory action research spanned an entire five years during which I spent many hours in workshops and debriefing sessions while being engaged in active participant observation. The study began as a quantitative study before it changed to a qualitative methodology. To obtain a research sample, I invited people from Pietermaritzburg and its surrounding areas to attend a stress- and trauma-healing workshop at Kenosis Retreat Centre, which was facilitated by Diakonia Council of Churches.
After obtaining consent from participants to volunteer in the Trauma Healing Pilot Project, participants completed the Harvard Trauma Questionnaire (HTQ Original Version). HTQ is designed to assess the mental health functioning of individuals who have experienced traumatic life events (Mollica 2007:12). The study began with 38 participants (15 men and 23 women), aged between 20 and 45 . All completed the questionnaire and returned it to me during the workshop. After data cleaning, 33 questionnaires were actually usable. Results showed that, of the 33 participants, 26 had either experienced or witnessed at least one traumatic event. Events ranged from rape, murder of close relatives, shot at but survived, stabbed, car accidents, abducted, sustaining serious injuries to the head, robbed at gun point, testing HIVpositive and other forms of violence.

\section{Re-authoring life narratives Storytelling}

After obtaining a research sample, storytelling was the first process in the re-authoring of the life narratives of trauma survivors. Van der Merwe and Gobodo-Madikizela (2008:viii-ix) point out that trauma survivors do have an ambivalent desire both to suppress their trauma and to talk about it. To talk about it is the best thing and yet would mean an extremely painful reliving of the event. So in order to survive, a trauma survivor would normally suppress the memory. Yet, paradoxically, it is precisely the confrontation of the suppressed memory that is needed for inner healing. Herman (1995) adds that the conflict between the will to deny horrible events and the will to proclaim them aloud is the central dialectic of psychological trauma. Wainrib (2006:27) contends that remembering and telling the truth about terrible events are essential tasks for both the healing of individual victims, perpetrators and families and the restoration of the social order.

To confront their suppressed or 'debilitating memory', all 38 participants attended the Stress and Trauma Healing Level 1 workshop at Kenosis from 30 October to 01 November 2009. This level focused on creating a safe space for trauma survivors to begin working through their trauma by telling their stories. It covered themes like understanding stress and trauma; establishing safety and trust; naming, mourning and grieving losses; effective ways of coping and encouraging healthy relationships. Participants were asked to draw their traumatic events on flip charts, which they used to share their stories in smaller groups. The drawings played a major role in helping storytellers to reorganise the events in chronological order. Although some people were afraid to confront their pain and others did not trust enough to share private memories in groups, the safe space encouraged them to share. One participant commented:

'Every time I tried to talk to my family about what happened [both her father and brother were killed] I cried... I was a shy person who was afraid to share my stories, even the happy ones. This was the first time in my life I shared my stories with people I did not know, and the group that I was part of really helped me 
because people were open and shared all their stories. Every one of my group was crying during storytelling. I felt comfortable being part of that group, and I asked myself, 'Why not share mine?' Although I felt pain, this helped me. I learnt that talking or sharing traumatic experiences with others is an important medicine to cure myself'.

Van der Merwe and Gobodo-Madikizela (2008:27) assert that reconstructing the trauma into a narrative form is one of the most crucial processes in the journey towards the healing of the victim. The reconstruction happens when we feel listened to.

\section{Mourning and grieving losses}

The second process focused on helping participants to name, mourn and grieve their losses. Mourning simply means an expression of grief and sorrow over that which is lost. Bartsch and Bartsch (1996:78) state that victims find healing when they are able to separate themselves from the events and from the perpetrators who have victimised them. One of the significant processes is when victims are able to name the events, understand what happened and mourn what was lost in order for them to gain control over their lives and heal. He adds that, by naming, re-telling and re-experiencing the story of trauma with a resource person, we frame it. By describing the event, it goes out of us, it goes 'out there'. Thus the event takes on a new meaning.

The losses that participants talked about in small groups covered many areas like the loss of loved ones or friends through death or separation and the loss of well-loved places or settings. It also covered the loss of opportunities, physical health, emotional health, marital relationships, being free to be a child, self-concept and faith and meaning in life.

\section{The survivors' reintegration process}

The third process sought to affirm the trauma survivors' dignity, hope and healthy identity as well as encouraging them towards healthy relationships. In her Assumptive world theory, Janoff-Bulman (1992:5) argues that traumatic events are psychologically distressing because they shatter some of the survivors' fundamental assumptions about the world. Most generally, at the core of our assumptive world, lie abstract beliefs about ourselves, the external world and the relationship between the two. When we experience a traumatic event, the effect is to 'shatter' our assumptive world or to render our assumptive world 'profoundly invalid'. Thus trauma destroys the belief that we are in control of our lives, leaving us shattered. Bartsch and Bartsch (1996:112) add that severe and traumatic stress shatters our dignity and self-respect as well as killing our belief that we are able to make a difference; our faith in life is shaken.

To facilitate the process of regaining dignity, participants took part in several sessions which focused on how they survived the traumatic experiences or loss. Any positive action they took during their traumatic experience was affirmed. These unique outcomes became the building blocks for an alternative story of their lives. Also, the connection with other people who experienced or witnessed traumatic events brought healing through identification.

Kitengie (2013) a participant and author of Why does the sun rise black? says:

The good news from the workshop on stress and trauma is that all the participants became my family members with whom my life experiences are shared openly and with encouragement. I am not alone in the jungle or the only one having these kinds of situations in life. These workshops opened ways through sharing of my personal life experiences with them and broke barriers of separation and distinction of otherness. (pp. 140-154)

His story is one of the many stories that were shared on this trauma project, and it was also published. The support from each other helped to recover faith, hope and meaning. It also facilitated the restoration of relationships that were shattered or disconnected by trauma.

\section{Training as caregivers}

The fourth process in the re-authoring of life narratives was training caregivers. Four months after the Level 1 workshop, in April 2010, 26 participants attended the Trauma Healing Workshop Level 2. This level continued the healing process by focusing on helping survivors to become caregivers. The process comprised themes like understanding yourself as a healer, exploring why you want to become a healer, how to take care of yourself as a caregiver and how to heal and inspire your community with faith and hope. At the end of the workshop, participants received certificates. Morgan (2000:90-91) states that '... certificates help celebrate the new story that emerges and to commemorate how the person has managed to overcome the problem to regain their life from its influence'. Indeed, participants showed signs of overcoming the victimhood forced upon them by trauma.

\section{Training as facilitators}

Caregivers found Levels 1 and 2 helpful, and they wanted to facilitate healing in their own communities and churches and in languages with which they would feel comfortable. I wondered what direction the study was going to take now, but as a participatory action researcher, I allowed myself to be led by them. As Müller (2004:304) puts it, practicaltheological research is not only concerned with describing and interpreting experiences but with deconstructing dominant discourses which prevent people from developing alternative interpretations and identities. Discourses of helplessness and victimhood were deconstructed, and participants found meaning in their traumatic experiences. This change of identity from victims to survivors and now wounded healers is evidence of the 'development of alternative interpretations and identities'.

Thus, in June 2010, 23 participants attended Level 3 Facilitator Training. After training, I accompanied them 
in their communities to do trauma awareness and later facilitated several Stress and Trauma Level 1 workshops. They actually facilitated the telling of traumatic stories to other Level-1 participants from their own communities.

\section{Documenting stories in a focus group}

The sixth part of the process was to document and publish life narratives into a book. Some facilitators requested this: 'We want to use our wounds to heal others.' They wanted to document their own stories and publish a book, which other people could read and find healing through identifying with them. Pederson (2014:350) supports the idea of documenting traumatic stories as a means to healing. He says that imaginative writing plays a role in engaging personal or collective pain. Indeed, creative language, like discursive language, can aid in the healing process, the recovery, the reconciliation and the rehabilitation of trauma survivors. He adds that, whilst literature may not be the only way of speaking about trauma, it remains a valuable tool in the struggle to reclaim our most painful experiences.

As a process of learning how to write publishable stories, we attended two story-writing workshops at Diakonia in Durban in 2011 where the Durban trauma facilitators joined the story-writing project. The process dragged on until the book was published late in 2013 by PACSA and Diakonia. It had the following title: Trees along the riverside: The stories of trauma facilitators in KwaZulu-Natal South Africa. In this handbook, participants recorded milestones on their journey towards healing or progression along the way (Morgan 2000:95). The writing itself was also therapeutic as writing helps us to express what has been suppressed, especially with painful and traumatic memories. This was a big milestone for the longitudinal study. On 08 December 2013, the book was launched at ESSA, Pietermaritzburg, and the speech each author gave was overwhelming. I remember some participants saying, 'Today we are authors also, we thought publishing books only belong to the academics'. Each author was given a set of ten books. They shared with their relatives and friends as witness to their healing and new identity. Healing from a 'victim identity' occurs when victims recover their dignity and re-integrate into their community with rightful respect from others and respect for others and for themselves. This type of healing is transformative. It transforms the way in which we think about ourselves and the world around us. We begin to think of ourselves as survivors of those events. Survivors are people who have been victims but who think of themselves as able to manage their lives, hold on to their self-respect and dignity and take on meaningful roles in their families, work, churches and communities (Bartsch \& Bartsch 1996:11-12).

Participants entered the study project as victims of stress and traumatic events. After working through their trauma, they no longer saw themselves as victims but as wounded healers and authors. Re-authoring conversations seek to create the possibility of the generation of alternative, preferred stories of identity (Carey \& Russell 2003:68). At the beginning of the project, we needed confidentiality to tell our stories because of the fear, shame, self-blame and guilt attached to them. However, after the healing processes, the very stories which needed a closet were published. Thus the stories are no longer private memories. They have become public memories.

\section{Analysing data}

After the stories were published, I obtained written consent from five authors whose stories I wanted to use as data for my doctoral thesis. Using the thematic analysis method, I established several concepts and categories to summarise key features of a large body of data. Braun and Clarke (2006:79) define thematic analysis as a method of identifying, analysing and reporting patterns (themes) within data.

To generate themes, I used the steps which Braun and Clarke propose: Firstly, I familiarised myself with data from the six life narratives by reading and re-reading them, writing down initial ideas. Secondly, I coded what I found to be interesting features of the data in a systematic fashion across the entire data set, collating data relevant to each code before searching for potential themes. I then gathered all data relevant to each potential theme. After checking if the potential themes work in relation to the extracts I coded, I came up with what Braun and Clarke (2006:87) call a 'thematic 'map' of the analysis'. Finally the themes were defined and named. The themes that were generated were related to the research aim.

\section{The effects of trauma on survivors Bio-psychosocial effects}

This section of the article discusses psychological, moral and spiritual injuries. It goes on to explore the role of 'posttraumatic spirituality' in the re-authoring of life narratives shattered by trauma. The study began as a critique of the bio-psychosocial approach to understanding the effects of trauma. The biopsychosocial approach recognises that trauma affects a person biologically, socially and psychologically. The South African Institute for Traumatic Stress (2009:46) elaborates that the biological is concerned with the physical effects of the trauma or with other somatic symptoms. The psychological is concerned with the psychological responses to stress and the impact that the trauma has on the client? The social is concerned with the impact on the family, social functioning and work life. Whilst the bio-psychosocial approach to understanding trauma was one dimension of this study, it did not address the moral and spiritual injuries which participants sustained during and after experiencing or witnessing traumatic events.

\section{Psychological injury}

Many of the research participants sustained psychological injury as they tried to make sense of their ordeal. The Harvard 
Trauma Questionnaire revealed the trauma symptoms some of them were experiencing. For example, some had recurrent thoughts or memories of the most hurtful or terrifying events they experienced, they were feeling as though the event was happening again and they suffered from recurrent nightmares, feeling jumpy, being startled easily and feeling irritable or having outbursts of anger. Others had trouble sleeping, avoided activities that reminded them of the traumatic or hurtful event, had sudden emotional or physical reactions when reminded of the most hurtful or traumatic events and were feeling ashamed of the hurtful or traumatic events that had happened to them, amongst others.

Gilchrist (n.d.:1) argues as follows: 'When a traumatic event occurs, the effect is to "shatter" the victim's assumptive world, or to deliver "profound invalidation" of that world". Caruth (1996:10) sees traumatic experience as 'unclaimed experience'. In trauma, the horrific moment arrives with such world-shattering force that it scrambles the brain's function, and the victim is unable to process the experience in a normal way. Caruth (1996:62) calls trauma a 'missed experience'. By this, he means that the shock of the mind's relationship to the threat of death is not the direct experience of the threat but the very missing of this experience. It is the fact that the trauma is not being experienced in time. It is not yet fully known. It is this lack of direct experience that, paradoxically, becomes the basis of the repetition of the nightmare.

What returned to haunt the research participants in this study through nightmares, flashbacks, and hallucinations is not only the reality of the traumatic experience but also the reality that its violence is not yet fully known. Trauma forced the self into hiding, and whilst the sensory manifold kept 'recording' sights, sounds, smells and feelings, the brain failed to work them through. Thus in a sense, as Caruth (1995:6) puts it, the videographer left, but the tape kept running. The trauma, then, is '... an event whose force is marked by its lack of registration' (Caruth 1995:6).

\section{Moral injury}

Some co-researchers sustained moral injury. Litz et al. (2009:699) argue that the majority of individuals have a strong moral code that they use to effectively navigate their lives. Morals are the personal and shared familial, cultural, societal and legal rules for social behaviour, either tacit or explicit. Morals are fundamental assumptions about how things should work and how one should behave in the world. However, when these morals are breached, a person may experience moral injury. Litz et al. (2009) defines moral injury as:

Potentially morally injurious events, such as perpetrating, failing to prevent, or bearing witness to acts that transgress deeply held moral beliefs, and expectations may be deleterious in the longterm, emotionally, psychologically, behaviourally, spiritually, and socially (p. 695)

Litz et al. (2009) add that moral injury involves an act of transgression that creates dissonance and conflict because it violates assumptions and beliefs about right and wrong and personal goodness. How this dissonance or conflict is reconciled is one of the key determinants of injury. Litz et al. (2009) argue that, if individuals are unable to assimilate or accommodate (integrate) the event within their existing self and relational schemas, they will experience guilt, shame and anxiety about the potential dire personal consequences (e.g. ostracisation). Thus poor integration leads to lingering psychological distress due to frequent intrusions.

Several research participants shared their experiences of moral injury. For example, Bridget Phillips (2013:32-47), author of The hard gravel road, sustained moral injury. She lost her father at the age of ten. The relatives shared the children to raise them, and Phillips was taken by her cousin (brother). When she turned eleven, he started raping her, and it went on for a year.

\section{Phillips (2013) says:}

Time went by so quickly. One year had passed and I had matured. I was doing almost everything myself. One night Daniel came into my room and said, 'It's cold so we are going to sleep in the same bed to keep each other warm.' He slept in my bed, held me and said, 'Do not tell your teacher that we slept in the same bed.' Some nights he slept in his room and on other nights he slept in my bed. I did not see anything wrong, until one night he started to touch me. It was not right for my brother to touch my breast and my private parts. He was my brother; in the African culture your cousin is like your brother. I started to cry, and in his words he said, 'I love you and care about you.' Slowly I became scared of my cousin and I didn't want to talk to anybody because I was warned not to tell. (p. 40)

The incest affected other areas of her life: 'I didn't want to go to school, my marks started going down, and slowly I went into a shell' (Phillips 2013:40).

Though 11 at the time, Phillips knew that the moral code or moral campus in the African culture does not make provision for sex between relatives, and she started to cry. The crying, however, did not help to stop her cousin. With both words of love and threats not to tell anyone, the typical language of the abuser, the sexual abuse went on for a year. She was morally injured because she was forced to commit indecent acts which transgressed or violated her deeply held assumptions and belief about morality. Phillips (2013) says:

It was not right for my brother to touch my breast and my private parts. He was my brother, in African culture your cousin is like your brother. (p. 40)

Her human freedom to choose to do what is right was taken away. Thus she would suffer physical, social or economic consequences if she resisted sexual abuse (PATH 2005:17). Thus her cousin wielded totalitarian control and overrode her will, which is tantamount to moral injury. Noma had nowhere to hide. She could not even seek help even when she needed it the most. Phillips (2013:40) says: 'Slowly I became scared of my cousin and I did not want to talk to anybody because I was warned not to tell'. 
She suffered complex-trauma. Herman (1992:120-121) states that a person experiences a complex-trauma syndrome when there is a history of subjection to totalitarian control over a prolonged period (months to years). Examples include being subjected to totalitarian systems in sexual and domestic life, including the survivors of domestic battering, physical or sexual abuse in childhood and organised sexual exploitation (Herman 1992:120-121).

During the storytelling process, Phillips expressed shame, guilt and a lot of anger towards her cousin for the incest and maltreatment she received. Lewis (1971) points out that shame involves a global evaluation of the self along with behavioural tendencies to avoid and withdraw. Litz et al. (2009:699) add that shame results in more toxic interpersonal difficulties such as anger and decreased empathy for others, and these experiences can, in turn, lead to devastating life changes. This explains why Phillips expressed a lot of anger during the Level-1 storytelling sessions. Generally, research has shown that shame is more damaging to emotional and mental health than guilt (Tangney, Stuewig \& Mashek 2007). Litz et al. (2009:699) assert that shame may be a more integral part of moral injury.

Talking about the experiences of war veterans in the United States of America in their book Soul repair: Recovering from moral injury after war, Nakashima and Lettini (2012) point out that the consequences of violating one's conscience, even if the act was unavoidable or seemed right at the time, can be devastating, and responses can include overwhelming depression, guilt and self-medication through alcohol or drugs. They contend that moral injury can lead victims to feelings of worthlessness, remorse and despair. As memory and reflection deepen, negative self-judgements can torment a soul for a lifetime. Thus moral injury destroys meaning and forsakes a noble cause. The consequences of these feelings become overwhelming, and the only relief a person may find is to commit suicide. Although none of the research participants committed suicide, few of them shared information about their attempts. For Phillips, it was rebellion against her mother. After she was rescued from the 'fangs' of her cousin, her moral campus was so affected that she began to engage in risky sexual behaviour, which resulted in a teenage pregnancy at the age of 15 .

Moral injury was a common experience amongst research participants. Some of the stories were loaded with shame, guilt and regret for the things that they had done, that was done to them and that they failed to do.

\section{Spiritual injury}

Traumatic experiences have the potential to lead to spiritual injury. Drescher and Foy (1995) state that traumatic events often lead to dramatic changes in survivors' worldviews so that fundamental assumptions about meaningfulness, goodness and safety shift negatively. For those whose core values are theologically founded, traumatic events often give rise to questions about the fundamental nature of the relationship between creator and humankind. Grant (1999) explains:

Traumatic experiences force victims to face issues lying outside the boundaries of personal and collective frames of reference. As a result, they are forced to confront psychological and spiritual challenges that are unfamiliar to the average person. (n.p.)

Sherman (2010:37) adds that traumatic events call into question basic human relationships; breach attachments of family, friendship, love and community; shatter the construction of the self that is formed and sustained in relations to others and undermine the belief systems that give meaning to human experiences.

Exposure to trauma invokes meaning questions. For example, from his studies amongst war veterans in the United States of America, Nelson-Pechota (2004) argues that exposure to traumatic combat experiences often leads to a search for meaning and purpose within a personal and collective sense - seeking the answers to a myriad of questions about the painful realities of warfare, the value of personal existence and the value of the human race. The faith that God is constantly available to respond to one's hopes, fears, anxieties and tragedies can be shattered. When this happens, individuals who are unable to resolve challenges to their moral and spiritual beliefs might find themselves in a state of spiritual alienation, which can take many forms. For example, a person may feel abandoned by God and, in his or her response, may reject God, feeling that God was powerless to help and therefore unavailable.

An example of the above is Chiya (2013:107-118), a research participant and the author of On my strong shoulders, who sustained spiritual injury due to complicated grief. She lost more than five loved ones in a space of a few years, including her fiancé. Chiya says that these losses made her stronger in God because she learnt to take care of others. However, she was thrown off balance when here next fiancé took ill. She was confronted with the impending death of another fiancé. As a woman who knew the power of prayer, she wrestled with God for his healing. She believed: 'Nothing is impossible if you believe in God.'

\section{Chiya (2013) says:}

I stayed with him [in the hospital from] morning till night. Whenever I tried to pray my sorrows were flooded in tears. I asked God, 'Ukuthi, why mina?' [Saying, why me?] When will I find happiness in my life? (p. 117)

Louw (2000:397) asserts that the search for the presence of God in suffering intensifies the question of theodicy. This causes a problematic understanding of God which leads to dysfunctional or pathological faith behaviour. For example, Chiya (2013) says:

His ... death put my life on hold. On 1 April 2001 his body was laid to rest in Howick Cemetery, the saddest day of my life. I told myself that God did not love me so I broke away from church for almost two years. I did not pray and if anyone mentioned God, I swore. (p. 118) 
Chiya's experience is a perfect example of what Louw calls, 'dysfunctional or pathological faith-behaviour' as a consequence of spiritual injury. Louw adds that intense pain creates the impression that God is absent. Chiya (2013:117) asked God, '"Ukuthi, why mina?" [Saying, why me?] When will I find happiness in my life?' She did not desire an answer. She experienced the absence of God. Louw (2000:397) clarifies that God's involvement with suffering becomes intensely problematic, especially when the believer confesses God's omnipotence. Chiya's (2013:118) God-image and belief that ' $n$ ] othing is impossible if you believe in God' was shattered. As a result, she abandoned God and anything to do with God for the next two years. So deep was her spiritual injury that she says: 'I did not pray and if anyone mentioned God, I swore.'

Stallinga (2013:20), in his article 'What spills blood wounds spirit ...', states that there are spiritual injuries that manifest in grief, loss, guilt, shame, lack of forgiveness, loss of meaning and purpose, loss of hope, loss of faith and a search for restoration and wholeness. Louw (2005:112) asserts that a crisis affects the spiritual realm as well because it invades the spirituality due to the interconnectedness between selfunderstanding and different God-images. Thus traumatic death rendered an 'absolute invalidation' of Chiya's faith, and she sustained spiritual injury.

\section{Implications of 'posttraumatic spirituality' in recovery from trauma}

In his doctoral thesis, Re-authoring life narratives of trauma survivors in KwaZulu-Natal: Spiritual perspective, Manda (2013) defines the term 'posttraumatic spirituality' to refer to the theologies, spiritual values or personal images and conceptions of God or one's objects of devotion that develop in the aftermath of a traumatic experience. The original understanding of the divine is shattered after the invasion of trauma in one's life. For example, the case of Chiya mentioned above demonstrates posttraumatic spirituality. Her God-images were shattered when she realised that the God, with whom nothing is impossible, did not save her fiancé's life. She abandoned God and church, and she would swear when someone mentioned God in her presence. Thus not only did trauma sever her relationship with God, but it also severed her from other support systems like the church and church friends that are crucial in the healing process of traumatised individuals.

Traumatic events destroy the victim's fundamental assumptions about the safety of the world, the positive value of the self and the meaningful order of creation (JanoffBulman 1992). They violate the victim's faith in a natural or divine order and cast the victim into a state of existential crisis. Chiya's case above revealed how trauma transgresses or violates the boundaries of spirituality.

Louw (2007:72) contends that images and conceptions of God play a decisive role for the 'healthy' functioning of mature faith. For example, Grant (1999) points out that a traumatic experience can break a person, destroying trust in God and the world. However, it can also provide a spiritual opening - a crack that opens the way to a deeper sense of life's meaning. Grant (1999) argues that trauma, in spite of its brutality and destructiveness, has the power to open victims to issues of profound existential and spiritual significance. Grant contends that if health is to be restored then the help of the Spirit and others is required. Acknowledging this fundamental dependency is a critical milestone on the healing path. Grant's assertion is supported by a body of literature documenting the propensity of individuals to seek religious or spiritual comfort following a traumatic event. For example, Baldacchino and Draper (2001:833-841) conducted a literature review of 187 articles on spirituality and health published between 1975 and 2001. They found that spiritual coping strategies - involving relationships with self, others, the Ultimate other or God or nature - were found to help individuals in coping with their ailments. This is because of finding meaning, purpose and hope, which may nurture individuals in their suffering. Thus the use of posttraumatic spirituality may enhance self-empowerment, leading to finding meaning and purpose in posttraumatic situations.

\section{Conclusion}

This article began as a critique of the bio-psychosocial approach to understanding the effects of trauma on individuals and communities. The bio-psychosocial approach is concerned with the effects that trauma has on the biological, social and psychological functioning of a human being. Working through trauma with trauma survivors in this longitudinal study has shown that some research participants sustained moral and spiritual injuries. Evidence shows that trauma took its toll on the lives of individuals physically, emotionally, psychologically as well as spiritually and in their relationship with themselves, others and God. The study has also shown that trauma can affect the moral aspect of a person, resulting in moral injury.

Therefore, the article argues that a bio-psychosocial approach is too limited for us to come up with a holistic understanding and treatment of the effects of trauma. It argues for an approach that integrates the moral and spiritual aspects. This integrated approach will have implications for a holistic understanding of the experiences of trauma survivors and enhance their treatment, healing and recovery.

\section{Acknowledgements Competing interests}

The author declares that he has no financial or personal relationship(s) that may have inappropriately influence him in writing this article.

\section{References}

Baldacchino, D. \& Draper, P., 2001, 'Spiritual coping strategies: A review of the nursing research literature', Journal of Advanced Nursing 34(6), 833-841. http://dx.doi. org/10.1046/j.1365-2648.2001.01814.x 
Bartsch, C. \& Bartsch, E., 1996, Stress and trauma healing: A manual for caregivers, Diakonia Council of Churches, Durban.

Braun, V. \& Clarke, V., 2006, 'Using thematic analysis in psychology', Qualitative Research in Psychology 3(2), 77-101. http://dx.doi.org/10.1191/1478088706qp063oa

Buckenham, K., 1999, Violence against women: A resource manual for the church in South Africa, PACSA, Pietermaritzburg.

Carey, M. \& Russell S., 2003, 'Re-authoring: Some answers to commonly asked questions', The International Journal of Narrative Therapy and Community Work 3, 60-71.

Caruth, C. (ed.), 1995, Trauma: Explorations in memory, The Johns Hopkins University Press, Baltimore.

Caruth, C., 1996, Unclaimed experience: Trauma, narrative, and history', The Johns Hopkins University Press, Baltimore.

Chiya, N., 2013, 'On my strong shoulders', in D.R. Haarhoff (ed.), Trees along the riverside: The stories of trauma facilitators in KwaZulu-Natal South Africa, pp. 107-118, PACSA, Pietermaritzburg.

Denis, P., Houser, S. \& Ntsimane, R., 2011, A journey towards healing: Stories of people with multiple woundedness in KwaZulu-Natal, Cluster Publications, Pietermaritzburg.

Drescher, K.D. \& Foy, D.W., 1995, 'Spirituality and trauma treatment: Suggestions for including spirituality as a coping resource', NCP Clinical Quarterly 5(1), viewed 16 February 2015, from http://montgomery.md.networkofcare.org/veterans/ library/article. .aspx?id=384

Gilchrist, K.J., (n.d.), A genealogy of suffering, viewed 20 December 2012, from http:// www.inter-disciplinary.net/probing-the-boundaries/wp>content/uploads/2012/ 10/gilchristsufpaper.pdf

Grant, R., 1999, 'Spirituality and trauma: An essay,' Journal of Traumatology 5(1E2) viewed 16 February 2015, from http://in-sigththerapy.blogspot.com/2013/06/ reactions-to-war-and-combat-combat.html

Herman, J.L., 1992, Trauma and recovery: The aftermath of violence from domestic abuse to political terror, Basic Books, New York.

Herman, J.L., 1995, 'Crime and memory', Bulletin of American Academy of Psychiatry and Law 23(1), 5-17.

Janoff-Bulman, R., 1992, Shattered assumptions: Towards a new psychology of trauma, Macmillan, New York.

Kaminer, D. \& Eagle, G., 2010, Traumatic stress in South Africa, Wits University Press, Johannesburg.

Kaplan, E.A. \& Wang, B. (eds.), 2004, Trauma and cinema: Cross-cultural explorations, Hong Kong University Press, Hong Kong.

Kitengie, J.E., 2013, 'Why does the sun rise black?', in D.R. Haarhoff (ed.), Trees along the riverside: The stories of trauma facilitators in KwaZulu-Natal South Africa, pp. 140-154, PACSA, Pietermaritzburg.

Landau, J., Mittal, M. \& Wieling, E., 2008, 'Linking human systems: Strengthening individuals, families, and communities in the wake of mass trauma', Journal of Marital Family Therapy 34(2), 193-209. http://dx.doi.org/10.1111/j.1752 0606.2008.00064.x

Lewis, H.B., 1971, Shame and guilt in neurosis, International University Press, New York.
Litz, B.T., Stein, N., Delaney, E., Lebowitz, L., Nash, W.P., Silva, C. \& Maguen, S. 2009, 'Moral injury and moral repair in war veterans: A preliminary model and intervention strategy', Clinical Psychology Review 29(8), 695-706. http://dx.doi. intervention strategy', Clinical
org/10.1016/j.cpr.2009.07.003

Louw, D.J., 2000, Meaning in suffering: A theological reflection on the cross and the resurrection for pastoral care and counseling, Peter Lang, Berlin.

Louw, D.J., 2005, Mechanics of the human soul: About maturity and life skills, Sun Press, Stellenbosch.

Louw, D.J., 2007, Cura vitae: Illness and the healing of life: A guide for caregivers, Lux Verbi, Wellington.

Manda, C.B., 2013, Re-authoring life narratives of trauma survivors in KwaZulu Natal: Spiritual perspective, PhD Thesis, Faculty of Theology, University of Pretoria, viewed 16 September 2014, from http://repository.up.ac.za/ handle/2263/40211?show=full

Mollica, R.F., 2007, Declaration: A new perspective on healing a violent world, viewed 8 June 2011, from http://healinginvisiblewounds.typad.com/healing_invisible_ wounds/2007/06/declaration-a-n.html

Morgan, A., 2000, What is narrative therapy?: An easy-to-read introduction, Dulwich Centre Publications, Adelaide, Australia.

Müller, J.C., 2004, 'HIV/AIDS, narrative practical theology, and postfoundationalism: The emergence of a new story', HTS Teologiese Studies/Theological Studies 60(1/2), 293-306.

Nakashima, R.B. \& Lettini, G., 2012, Soul repair: Recovering from moral injury after war, Beacon Press Books, Boston.

Nelson-Pechota, M., 2004, Spirituality and PTSD in Vietnam combat veterans, viewed 29 December 2012, from http://www.vietnamveteranministers.org/spirituality intro.htm

PATH, 2005, Researching violence against women: A practical guide for researchers and activists, viewed 16 February 2015, from http://www.path.org/publications/ files/GBV_rvaw_ch1.pdf

Pederson, J., 2014, 'Speak, trauma: Toward a revised understanding of literary trauma theory,' Narrative 22(3), 349-350. http://dx.doi.org/10.1353/nar.2014.0018

Phillips, B.D., 2013, 'The hard gravel road', in D.R. Haarhoff (ed.), Trees along the riverside: The stories of trauma facilitators in KwaZulu-Natal South Africa, pp. 32-47, PACSA, Pietermaritzburg.

Sherman, N., 2010, The untold war: Inside the hearts, minds, and souls of our soldiers, WW Norton \& Company, New York.

South African Institute for Traumatic Stress (SAITS), 2009, The specialist resource for traumatic stress practitioners and frontline workers, SAITS, Johannesburg.

Stallinga, B.A., 2013, 'What spills blood wounds spirit: Chaplains, spiritual care, and operational stress injury', Online Journal of Reflective practice: Formation and supervision in ministry $33,13-31$.

Tangney, J.P., Stuewig, J. \& Mashek, D.J., 2007, 'Moral emotions and moral behavior', Annual Review Psychology 58, 345-372. http://dx.doi.org/10.1146/annurev. psych.56.091103.070145

Van der Merwe, C. \& Gobodo-Madikizela, P., 2008, Narrating our healing: Perspectives on working through trauma, Cambridge Scholars Publishing, Newcastle.

Wainrib, B., 2006, Healing crisis and trauma with mind, body, and spirit, Springer Publishing Company, New York. 